\title{
LOW HDL-CHOLESTEROL LEVELS ARE ASSOCIATED WITH A DECREASED MONOCYTE ACTIVITY AND INFLAMMATION IN CARRIERS
} Amsterdam UMC OF LCAT MUTATION

Chiara Pavanello ${ }^{1}$, Kang H Zheng ${ }^{2}$, Johan G Schnitzler ${ }^{3}$, Jeffrey Kroon ${ }^{3}$, Miranda Versloot ${ }^{3}$, Johannes HM Levels ${ }^{3}$, Laura Calabresi ${ }^{1}$, Erik SG Stroes ${ }^{2}$, Siroon Bekkering 3,4

${ }^{1}$ Centro E. Grossi Paoletti - DiSFeB, Università degli Studi di Milano, Italy

${ }^{2}$ Vascular Medicine, Amsterdam University Medical Center, Amsterdam, The Netherlands

${ }^{3}$ Experimental Vascular Medicine, Amsterdam University Medical Center, Amsterdam, The Netherlands

${ }^{4}$ Department of Internal Medicine, Radboud University Medical center, Nijmegen, The Netherlands

\section{BACKGROUND \& AIM}

Epidemiological studies have shown an inverse relationship between low HDL-cholesterol levels and CHD. Besides the capacity in promoting cholesterol efflux, HDL can contribute to atheroprotection through the modulation of the immune response. As monocytes are the major contributors to the underlying inflammation in atherosclerosis there is the need to study the effect of HDL on monocyte phenotype. Animal and in vitro data are already available, while in vivo data in human are lacking. Aim of this study is to evaluate the effect of genetic HDL deficiency, specifically determined by mutations in LCAT gene, on monocyte immunophenotype and function.

\section{METHODS \& RESULTS}

- Carriers of LCAT mutation

- HDL-C $<1 \mathrm{mmol} / \mathrm{L}(40 \mathrm{mg} / \mathrm{dL})$

- Absence of cardiovascular disease, diabetes mellitus, CKD, metabolic syndrome

\section{CLINICAL AND BIOCHEMICAL PROFILE OF STUDY SUBJECTS}

\begin{tabular}{lcccc}
$\begin{array}{c}\text { Number of } \\
\text { mutant LCAT } \\
\text { alleles }\end{array}$ & $\begin{array}{c}\text { Two } \\
(\mathrm{n}=5)\end{array}$ & $\begin{array}{c}\text { One } \\
(\mathrm{n}=7)\end{array}$ & $\begin{array}{c}\text { Zero } \\
(n=9)\end{array}$ & -value \\
\hline Age $($ years $)$ & $44.0 \pm 7.9$ & $46.6 \pm 6.4$ & $41.2 \pm 4.0$ & 0.78 \\
Gender $(\mathrm{M} / \mathrm{F})$ & $1 / 4$ & $4 / 3$ & $5 / 4$ & 0.37 \\
BMl $\left(\mathrm{kg} / \mathrm{m}^{2}\right)$ & $25.1 \pm 1.1$ & $26.5 \pm 1.8$ & $24.5 \pm 1.3$ & 0.62 \\
Smoking $(\mathrm{n}, \%)$ & $1(20)$ & $2(29)$ & $5(44)$ & 0.62 \\
TC $(\mathrm{mg} / \mathrm{dl})$ & $154.0 \pm 25.9$ & $189.4 \pm 10.0$ & $208.5 \pm 9.6$ & 0.05 \\
TG $(\mathrm{mg} / \mathrm{dl})$ & $173(118-356)$ & $125(101-206)$ & $113(93-128)$ & 0.09 \\
LDL-C $(\mathrm{mg} / \mathrm{dl})$ & $121.0 \pm 23.9$ & $134.2 \pm 9.8$ & $121.5 \pm 7.7$ & 0.71 \\
HDL-C $(\mathrm{mg} / \mathrm{dl})$ & $7.3 \pm 1.7$ & $37.9 \pm 2.5$ & $63.4 \pm 5.9$ & $<0.0001$ \\
ApoA-l $(\mathrm{mg} / \mathrm{dl})$ & $27.0 \pm 7.2$ & $88.9 \pm 3.5$ & $121.1 \pm 7.9$ & $<0.0001$ \\
ApoB $(\mathrm{mg} / \mathrm{dl})$ & $116.6 \pm 22.9$ & $103.6 \pm 6.1$ & $93.9 \pm 2.9$ & 0.33 \\
Glucose $(\mathrm{mg} / \mathrm{dl})$ & $93.2 \pm 7.5$ & $74.1 \pm 2.1$ & $87.1 \pm 4.2$ & 0.03 \\
\hline
\end{tabular}

Data are expressed as mean \pm SD and $\mathrm{n}(\%)$ for categorical variable.

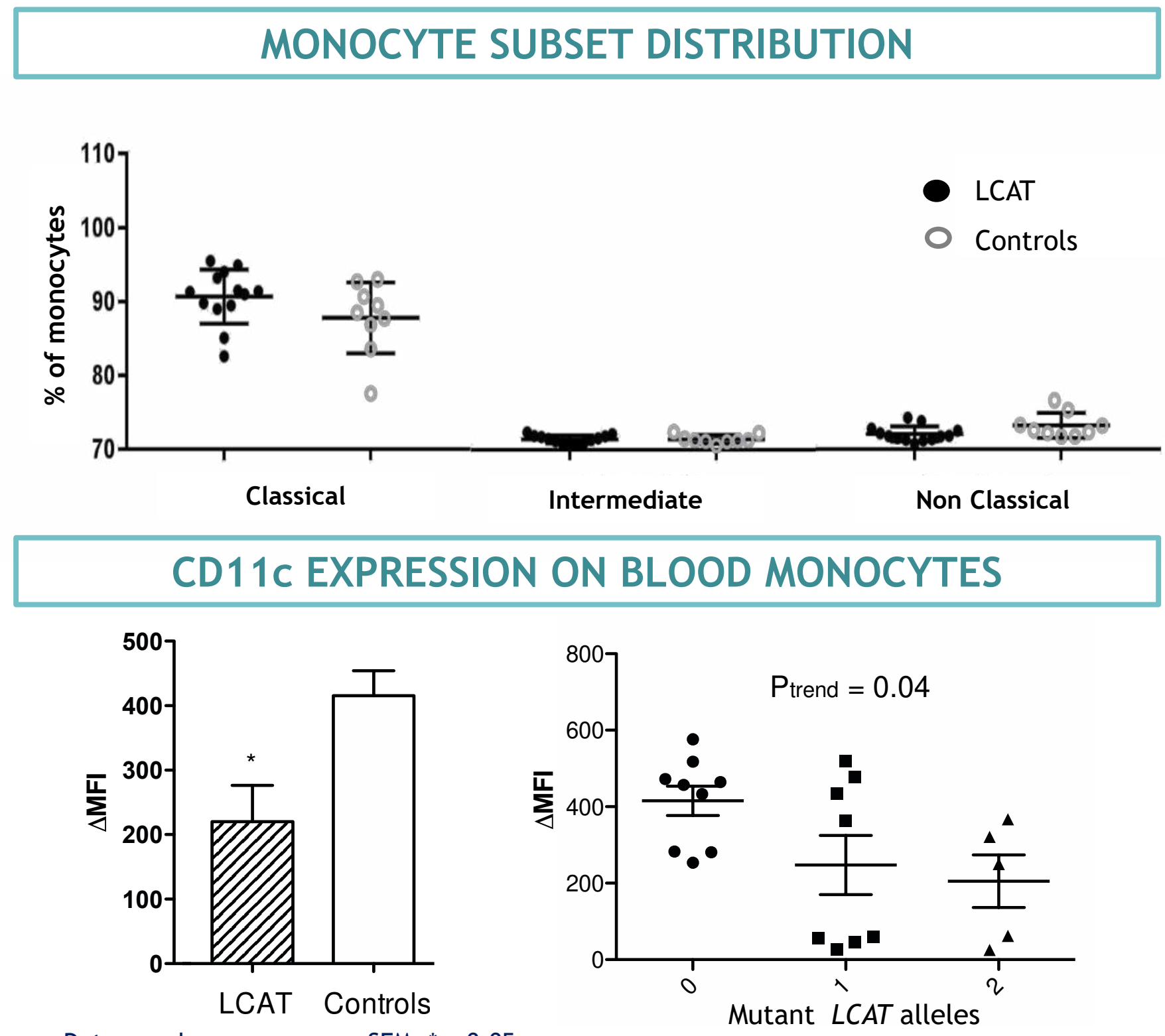

Data are shown as mean \pm SEM. * $<0.05$

\section{ACTIVATION MARKERS}

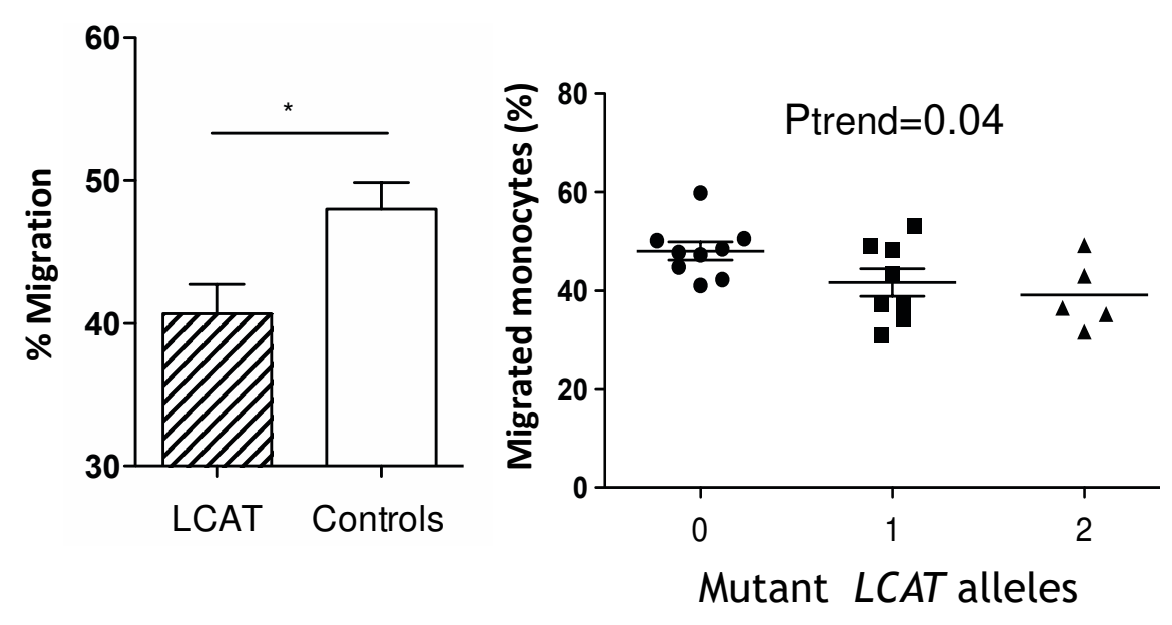

Data are shown as mean \pm SEM; * $<0.05$
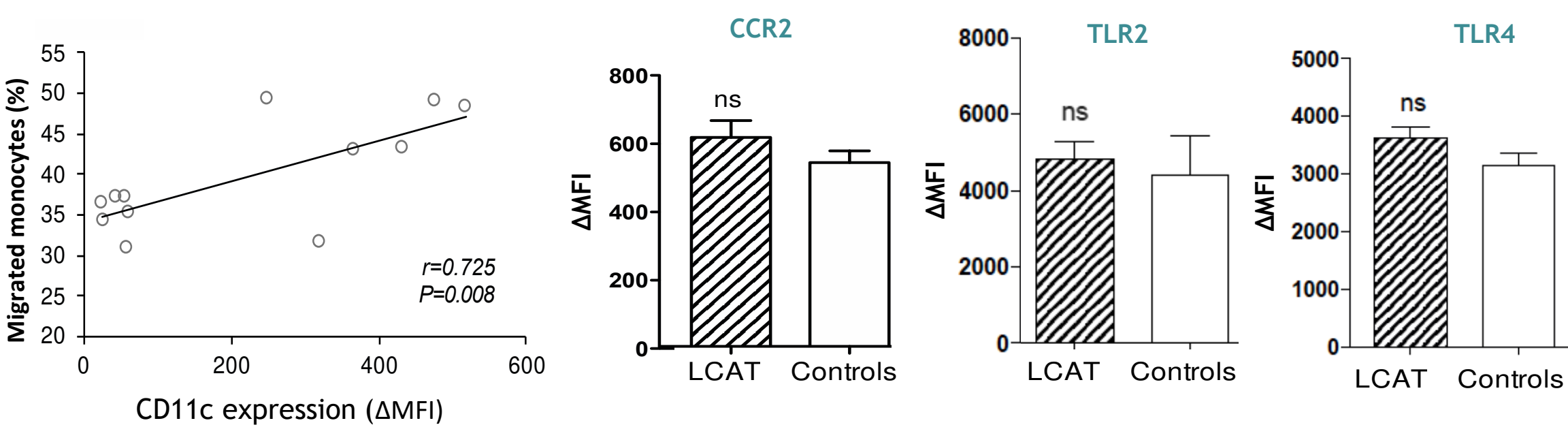

Data are shown as mean $\pm \mathrm{SEM} ;{ }^{*}<0.05$

\section{CYTOKINE PRODUCTION CAPACITY}
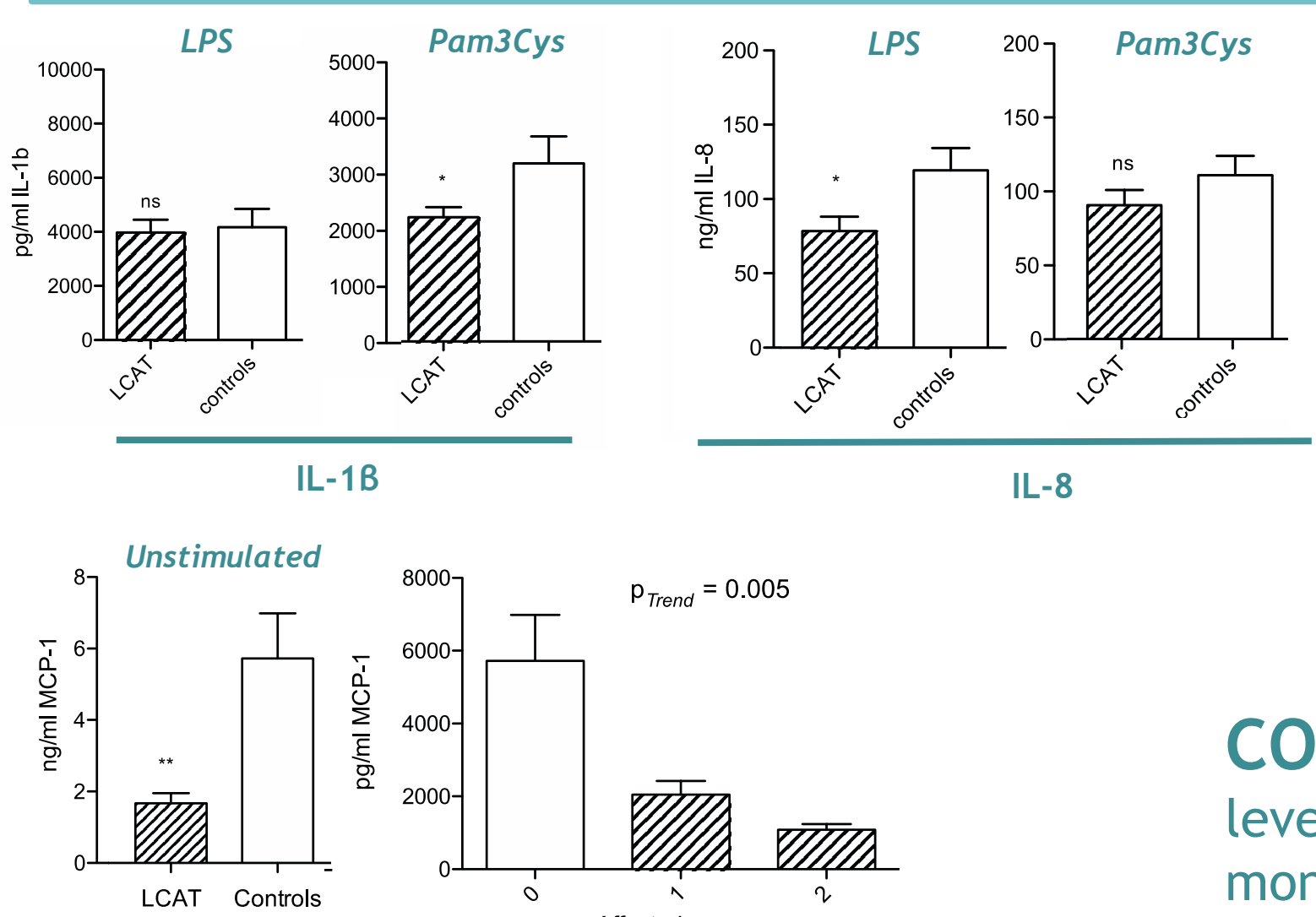

$\mathrm{p}_{\text {Trend }}=0.005$
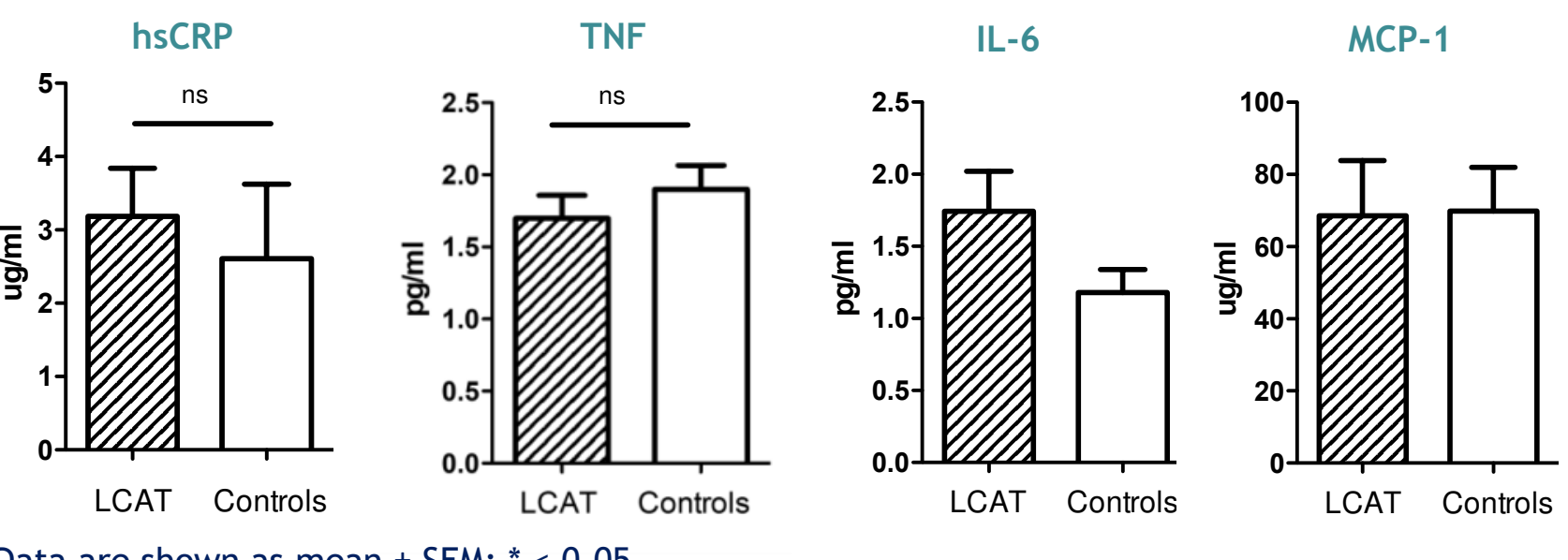

Data are shown as mean $\pm \mathrm{SEM} ;{ }^{*}<0.05$

\section{PLASMA CYTOKINES}

